Check for updates

Cite this: RSC Adv., 2018, 8, 17837

Received 26th January 2018

Accepted 21st April 2018

DOI: $10.1039 / c 8 \mathrm{ra00820e}$

rsc.li/rsc-advances

\section{An antibiotic agent pyrrolo[1,2-a]pyrazine-1,4- dione, hexahydro isolated from a marine bacteria Bacillus tequilensis MSI45 effectively controls multi-drug resistant Staphylococcus aureus $\dagger$}

\author{
George Seghal Kiran, ${ }^{a}$ Sethu Priyadharsini, ${ }^{a}$ Arya Sajayan, ${ }^{a}$ Amrudha Ravindran ${ }^{a}$ \\ and Joseph Selvin (D) *b
}

Sponge associated bacteria are a rich source of bioactive secondary metabolites. This study aims to isolate bacteria producing antimicrobial agents from a marine sponge, Callyspongia diffusa. A total of fifty-six bacteria were isolated and screened for antibacterial activity against multidrug resistant $S$. aureus. Based on the 16S rRNA sequence and phylogenetic analysis the antimicrobial producer strain MSI45 was identified as a novel Bacillus tequilensis. The culture conditions of strain MSI45 were optimized to enhance the yield of the antimicrobial compound. The antimicrobial compound was purified using a silica gel column chromatography and high performance liquid chromatography. On the basis of spectroscopic analysis such as FT-IR, NMR and GC-MS, the bioactive metabolite was identified as pyrrolo[1,2-a]pyrazine-1,4-dione, hexahydro. The extracted compound MSI45 showed a potent inhibitory effect on multidrug resistant $S$. aureus with an MIC of $15 \pm 0.172 \mathrm{mg} \mathrm{L}^{-1}$ and MBC of $20 \pm 0.072 \mathrm{mg} \mathrm{L}^{-1}$. The compound was non-hemolytic and showed high antioxidant activity. The antioxidant activity may increase the efficacy and safety of the molecule in drug development. Hence, this compound produced by Bacillus tequilensis MSI45 could have potent antimicrobial and antioxidant activity against S. aureus infection.

\section{Introduction}

The emergence of multidrug resistant (MDR) bacterial pathogens has posed a major threat to the public as the bacteria develop resistance against existing antimicrobial agents. ${ }^{1}$ Hence, the screening of a new class of anti-infective compounds is essential to treat major infectious diseases. Microbes surviving in profoundly hostile conditions usually produce secondary metabolites to repress the settlement of ecological competitors. ${ }^{2}$ Marine sponges and their microbial symbiosis is a unique ecological phenomenon which serves as the reservoir of novel bioactive molecules. ${ }^{3}$ More than 250 novel compounds are reported every year from marine sponges. ${ }^{4}$ Moreover, sponge derived metabolites are important substances which act as anti-inflammatory and anticancer agents. ${ }^{5}$ Marine sponge associated Bacillus can produce anticholinesterase enzyme which can degrade acetylcholine in the brain. ${ }^{6}$ Streptomyces spp. is the most widely explored bacterial species from Indian coast

\footnotetext{
${ }^{a}$ Department of Food Science and Technology, Pondicherry University, India ${ }^{b}$ Department of Microbiology, Pondicherry University, India. E-mail: josephselvinss@ gmail.com
}

$\dagger$ Electronic supplementary information (ESI) available. See DOI: $10.1039 / \mathrm{c} 8 \mathrm{ra} 00820 \mathrm{e}$ for the production of antimicrobial compounds. ${ }^{3}$ Progress in genome mining and metagenomic approaches has led to the manipulation of sponge associated microbial diversity and exploration of complex biosynthetic pathways of marine natural products. ${ }^{7}$ Different classes of compounds such as bioactive fatty acids, alkaloids, terpenes, sterols, cyclic peptides, peroxides, and amino acid derivatives are reported to be produced by sponges and their associated microbes. ${ }^{8-16}$ Bioactive peptides derived from the sponges are of non-ribosomal origin and contain unusual amino acids. ${ }^{3,17}$ Bacillus sp. are known for their high probiotic potential and more than 200 antibiotics have been produced by Bacillus and these antibiotics differ both in activity and structure. ${ }^{18}$ They are well known producers of antimicrobial compounds such as bacteriocin like inhibitory substances (BLIS) iturin, surfactin, fengycins and bacteriocins. ${ }^{19}$ Ribosomally active antibiotics showed decreased virulence secretion in S. aureus when compared to cell wall active antibiotics such as beta lactams which increases the exotoxin production. ${ }^{20}$ The greatest issue of multidrug resistance is associated with the Gram-positive bacteria such as Pneumococci, Enterococci and Staphylococci among which the S. aureus is of much concern because of its virulence, pathogenicity, adaptability in diverse habitats, ability to cause severe infections and mortality. Even when new antibiotics are used against $S$. aureus 
it develops effective mechanism to neutralise them. Hence, this study was focused to develop antimicrobial agent from marine bacteria against $S$. aureus. The $S$. aureus used in this study was resistant to all antibiotics including vancomycin and hence, we aimed to screen the antibacterial compound from a marine sponge associated bacteria. In this study, we report a novel Bacillus tequilensis MSI45 isolated from a marine sponge which exhibited potent antimicrobial and antioxidant activities against MDR $S$. aureus. The compound was structurally characterized by FT-IR, GC-MS and NMR. The active compound was identified as pyrrolo[1,2-a]pyrazine-1,4-dione,hexahydro.

\section{Materials and methods}

\subsection{Sponge collection and isolation of bacteria}

The marine sponge Callyspongia diffusa was collected by scuba diving at Vizhinjam (Kerala) coast located in southwest coast of India at a depth of 1 meter and 1500 meters away from the sea shore. The collected sponge was rinsed with sterile seawater to remove any adhered exogenous material and processed for the isolation of microorganisms. The rinsed sponge was then cut into small pieces using a sterile blade. A few drops of sterile distilled water were added, and the pieces were crushed using a sterile mortar and pestle. Then, it was serially diluted and plated on to Zobell Marine Agar (these ZMA, Himedia plates streaked with samples were incubated at $30{ }^{\circ} \mathrm{C}$ for $48 \mathrm{~h}$ ). Morphologically distinct colonies were selected and then restreaked till the pure cultures were obtained..$^{21}$

\subsection{Screening for antimicrobial activity}

The antibiotic resistance pattern of clinical isolates (13 S. aureus phenotypes) were collected from the clinical laboratories (Puducherry) and were screened against antibiotics (Himedia) such as ampicillin $10 \mathrm{mcg}$ per disc, azithromycin $15 \mathrm{mcg}$ per disc, chloramphenicol $30 \mathrm{mcg}$ per disc, ciprofloxacin $5 \mathrm{mcg}$ per disc, erythromycin $15 \mathrm{mcg}$ per disc, gentamicin $10 \mathrm{mcg}$ per disc, kanamycin $30 \mathrm{mcg}$ per disc, mecillinam $10 \mathrm{mcg}$ per disc, penicillin-G 10 units per disc and vancomycin $30 \mathrm{mcg}$ per disc as per the Clinical \& Laboratory Standards Institute: CLSI Guidelines (2013). The phenotypes (6) showed complete antibiotic resistance was selected for the activity screening.

The isolated colonies were cultivated on Zobell marine broth (Himedia) at $28^{\circ} \mathrm{C}$ for $96 \mathrm{~h}$ at $200 \mathrm{rpm}$. The cell free supernatant (CFS) was obtained by centrifugation (Eppendorff) at $10621 \times g$ for $15 \mathrm{~min}$ and was used for the screening of antimicrobial activity by agar well diffusion assay. ${ }^{22}$ Muller Hinton agar (MHA) plates were prepared and overnight grown culture of $S$. aureus was swabbed on the surface of MHA plates. Then wells were made using a sterile steel cork borer and the wells were filled with $50 \mu \mathrm{l}$ of cell free supernatant (CFS) and incubated at $37^{\circ} \mathrm{C}$ for $24 \mathrm{~h}$. Later the plates were inspected for zone formation.

\subsection{Identification of antimicrobial producer}

The potent antimicrobial producer MSI45 was morphologically and physiologically characterised by the Logan and Berkley's method. ${ }^{23}$ Genomic DNA of the isolate MSI45 was extracted using a genomic DNA extraction kit (sigma). Universal 16S rRNA eubacterial primer (5'-GAGTTTGATCCTGGCTCAG-3'; $5^{\prime}$ AGAAAGGAGGTGATCCAGCC-3') was used for the amplification of DNA. The 16S rRNA gene sequence obtained from the isolate MSI45 was compared with other bacterial sequences using NCBI mega BLASTn (http://blast.ncbi.nlm.nih.gov/Blast.cgi) for their pair wise identities. Multiple alignments of these sequences were carried out by Clustal W 1.83 version of EBI (www.ebi.ac.uk/cgi-bin/clustalw/) with 0.5 transition weight. Phylogenetic trees were constructed in MEGA 7.0 version (www.megasoftware.net) using a maximum parsimony algorithm.

\subsection{Screening of culture medium for the production of antimicrobial compound}

To study the effect of culture media on the production of antibacterial compounds $50 \mu \mathrm{l}$ from overnight grown culture of MSI45 was inoculated into $100 \mathrm{ml}$ of different media such as nutrient broth supplemented with $2 \% \mathrm{NaCl}$, Luria Bertani broth, modified marine broth, starch casein broth, and Zobell marine broth (Himedia). Each culture medium was then incubated at $28{ }^{\circ} \mathrm{C}$ for $72 \mathrm{~h}$. After incubation cell free supernatant was obtained by centrifugation at $10621 \times g$ for $15 \mathrm{~min}$. Then antibacterial activity of the CFS separated from different media was determined using a agar well diffusion assay as mentioned above.

\subsection{Optimization of process parameters}

In addition to the production media, various carbon, nitrogen sources and salt concentrations were optimized. Carbon sources used in the optimization process include $1 \%$ each of starch, glucose, sucrose and lactose and nitrogen sources used were ammonium nitrate, beef extract peptone and yeast extract. The effective carbon and nitrogen sources were further optimized by varying the concentration of chosen carbon and nitrogen source in increasing increments from 1-5\%. In addition, the effect of cultural conditions like varying salt concentration of $1-4 \% \mathrm{NaCl}$ and different temperature ranging between 20 to $40{ }^{\circ} \mathrm{C}$ and $\mathrm{pH} 4.0-9.0$ were optimized during the process development. The optimum cultural conditions and nutritional supplements required for optimum growth and enhance the yield of antimicrobial compound was determined by a well diffusion assay as described above.

\subsection{Screening of solvent for the extraction of antimicrobial compound MSI45}

The CFS of MSI45 was mixed with an equal volume of six different solvents such as chloroform, ethyl acetate, ethanol, dimethyl ether, dimethyl sulfoxide and methanol in separate extraction flasks and kept for overnight incubation at $4{ }^{\circ} \mathrm{C}$. The solvents were then evaporated in a rotary evaporator (Yamato) and the remaining residues were concentrated in vacuum concentrator (Labconco) and lyophilised in a lyophilizer (Yamato). The lyophilised compounds were dissolved at a concentration of $50 \mathrm{mg} \mathrm{L}^{-1}$ and from this $100 \mu \mathrm{l}$ of the compound MSI45 was tested for antimicrobial activity using a well diffusion assay. 


\subsection{Purification of antimicrobial compound}

The lyophilized compound from MSI45 was dissolved in DMSO at a concentration of $100 \mu \mathrm{g} \mathrm{ml}^{-1}$ and subjected to silica gel thin layer chromatography (TLC) using chloroform methanol and water (60:30:10) as the solvent system. The lyophilized compound was purified by using a silica gel column chromatography with chloroform, and methanol $(6: 4 \mathrm{v} / \mathrm{v})$ was used as the eluting solvent. The purified fractions were checked for bioactivity using a well diffusion assay against $S$. aureus. Further, the active fractions were purified by a HPLC using the same solvent system used for column chromatography with a flow rate of $0.5 \mathrm{ml} \mathrm{min}{ }^{-1}$. The purified active fraction of MSI45 was checked for hemolysis using 5\% of sheep blood agar plate. ${ }^{24}$ The purified active compound was subjected to a Fourier transform infrared spectrophotometer (Perkin Elmer, USA). A constituent of the metabolite was investigated using a gas chromatography (GC) (Perkin Elmer Autosystem XL GC-TurboMass, USA). The data was processed by a GC-MSD, Chemstation column conditions were programmed as column oven temperature $150{ }^{\circ} \mathrm{C}(4 \mathrm{~min}) 4^{\circ} \mathrm{C} \mathrm{min}{ }^{-1}$, temperature of inject port $250{ }^{\circ} \mathrm{C}$ and detector port $280{ }^{\circ} \mathrm{C}$. The peaks of the gas chromatography were subjected to mass spectral analysis and the spectra were analyzed by NIST MS search (version 2.0). ${ }^{1} \mathrm{H}$ and ${ }^{13} \mathrm{C}$ NMR spectra was acquired by dissolving the purified compound in deuterated DMSO at a concentration of $10 \mathrm{mg} \mathrm{ml}^{-1}$ and analyzed on a Bruker Avance II 500 Spectrophotometer (Bruker BioSpin AG, Switzerland) at $22{ }^{\circ} \mathrm{C}$.

\subsection{Determination of minimum inhibitory concentration (MIC)}

The MIC of MSI45 was determined by a broth microdilution method in 96-well microtiter plates according to the EUCAST standards for testing antimicrobial susceptibility ${ }^{25}$ with suitable modifications. Briefly, about $10^{8}$ cells per $\mathrm{ml}$ of bacterial suspension was subsequently diluted to $1: 300$ in tryptic soy broth. Different concentrations (10, 20, 30, 40, 50, 100, 150, $\left.200 \mathrm{mg} \mathrm{L}^{-1}\right)$ of MSI45 extract were dissolved in water and were used to determine MIC. To the sterile flat bottom 96-well plate $200 \mu \mathrm{l}$ of the diluted bacterial suspension and varying concentration of MSI45 was added and the cultures were incubated at $37^{\circ} \mathrm{C}$ for $24 \mathrm{~h}$. Wells with $S$. aureus alone served as positive control and wells with water served as negative control. The MIC was determined as the lowest concentration of MSI45 for which no visible bacterial growth was observed after $24 \mathrm{~h}$ of incubation. To determine the minimum bactericidal concentration (MBC), the CFU ml ${ }^{-1}$ was further evaluated in broth culture from wells without visible growth. All the experiments were performed in triplicates and repeated several times. The lowest concentration of the extract that showed reducing number of viable cells by at least three orders of magnitude was considered as MBC according to the recommendation of the European Committee for Antimicrobial Susceptibility Testing (EUCAST) of the European Society of Clinical Microbiology and Infectious Diseases (ESCMID). ${ }^{\mathbf{2 6}}$

\subsection{Time-kill assay}

Time-kill studies were performed according to the method described. ${ }^{27}$ Exponential phase colonies of $S$. aureus cells $\left(10^{6}\right.$ CFU ml $\mathrm{m}^{-1}$ ) were allowed to grow in a 6 deep well plates in triplicates and treated with MSI45 of different concentration of $1 \times$ MIC, $2 \times$ MIC, $4 \times$ MIC, $8 \times$ MIC to a final concentration of $80 \mathrm{mg} \mathrm{L}{ }^{-1}$ and incubated at $37^{\circ} \mathrm{C}$, for $12 \mathrm{~h}$ and then $200 \mu \mathrm{l}$ of respective samples were serially diluted in $10 \mathrm{mM} \mathrm{MgSO}_{4}$ and $\mathrm{CFU} \mathrm{ml^{-1 }}$ of $S$. aureus were checked in varying time intervals

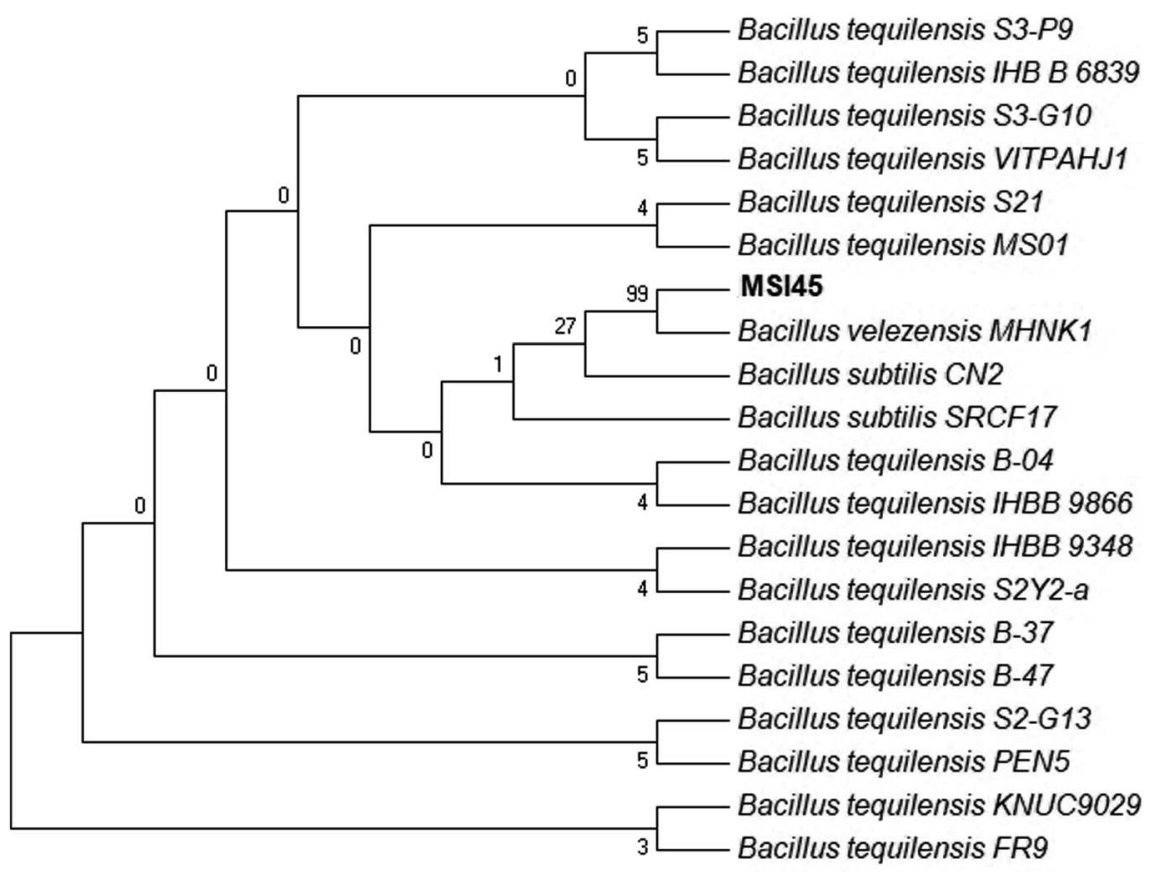

Fig. 1 Phylogenetic tree of MSI45 shows representatives of Bacillus tequilensis. The tree was inferred using maximum parsimony method. 


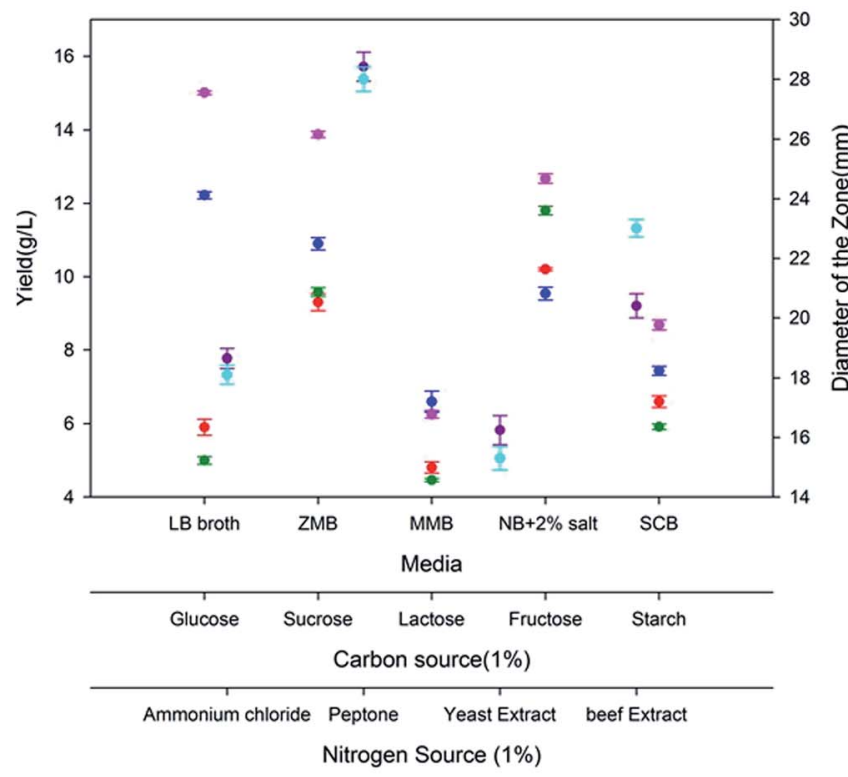

- Media vs Yield

- Media vs Diameter of the Zone

- Carbon source vs Yield ( $g / L$ )

- Carbon source vs Diameter of the Zone (mm)

Nitrogen source vs Yield (g/L)

Nitrogen source vs Diameter of the zone $(\mathrm{mm})$

A

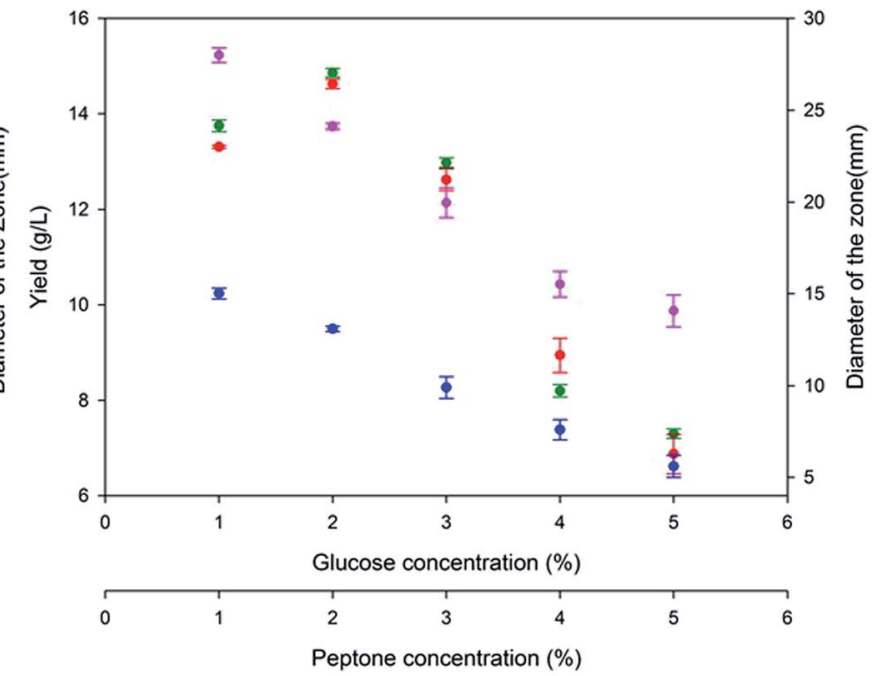

- Glucose concentration (\%) vs Yield(g/L)

- Glucose concentration (\%) vs Diameter of the zone (mm)

- Peptone concentration (\%) vs Yield(g/L)

Peptone concentration (\%) vs Diameter of the zone $(\mathrm{mm})$
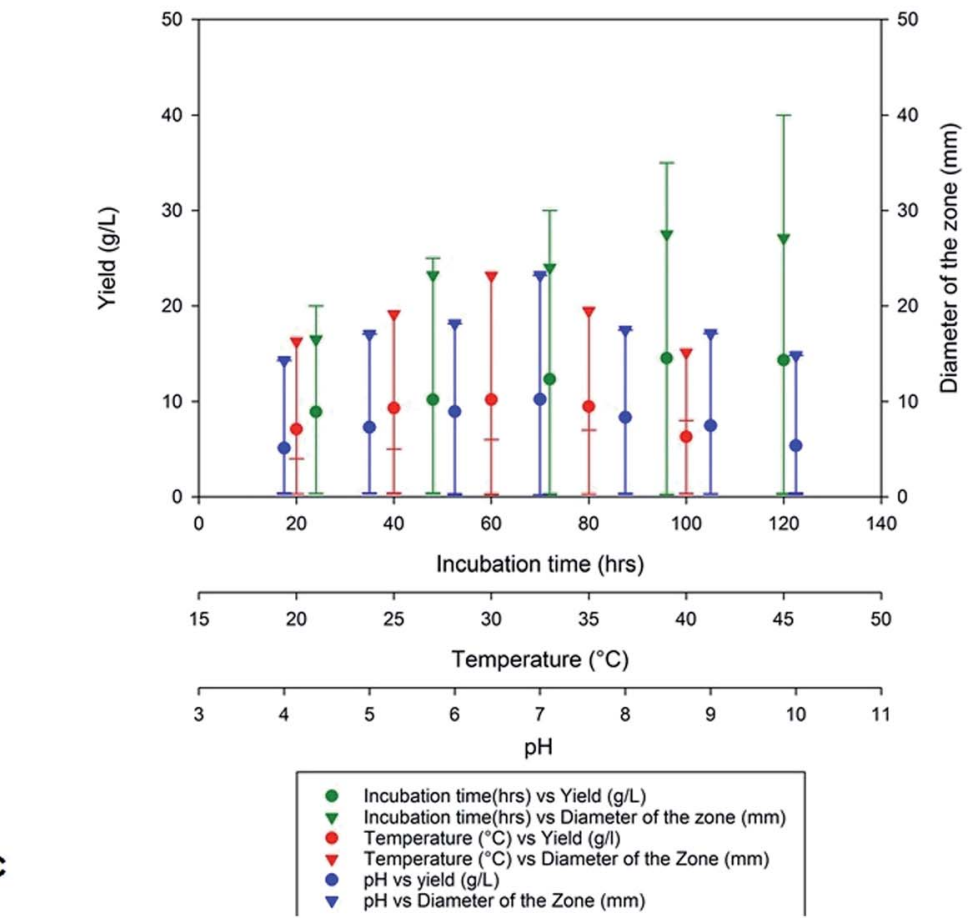

Fig. 2 Optimization of nutritional and physical parameters for the growth of MSI45 and production of antimicrobial compound.

by plating on TSA plates (tryptic soya agar) for enumeration of colony forming units (CFU).

\section{Antioxidant activity}

Antioxidant activity of the compound from MSI45 was determined using a DPPH radical scavenging assay, ${ }^{28}$ with necessary modifications. $0.2 \mathrm{ml}$ of different concentrations of the compound MSI45 $\left(25,50,75,100,125\right.$ and $\left.150 \mu \mathrm{g} \mathrm{ml}^{-1}\right)$ were added to $2.4 \mathrm{ml}$ of $0.1 \mathrm{mM}$ DPPH methanol solution. The assays were performed in triplicates, ascorbic acid served as the positive control and methanol was used as a blank. The assay mixture was vortexed and incubated in dark at $25{ }^{\circ} \mathrm{C}$ for $60 \mathrm{~min}$. The process of decolourization was recorded at $520 \mathrm{~nm}$ using a Shimadzu UV-VIS spectrophotometer. The 


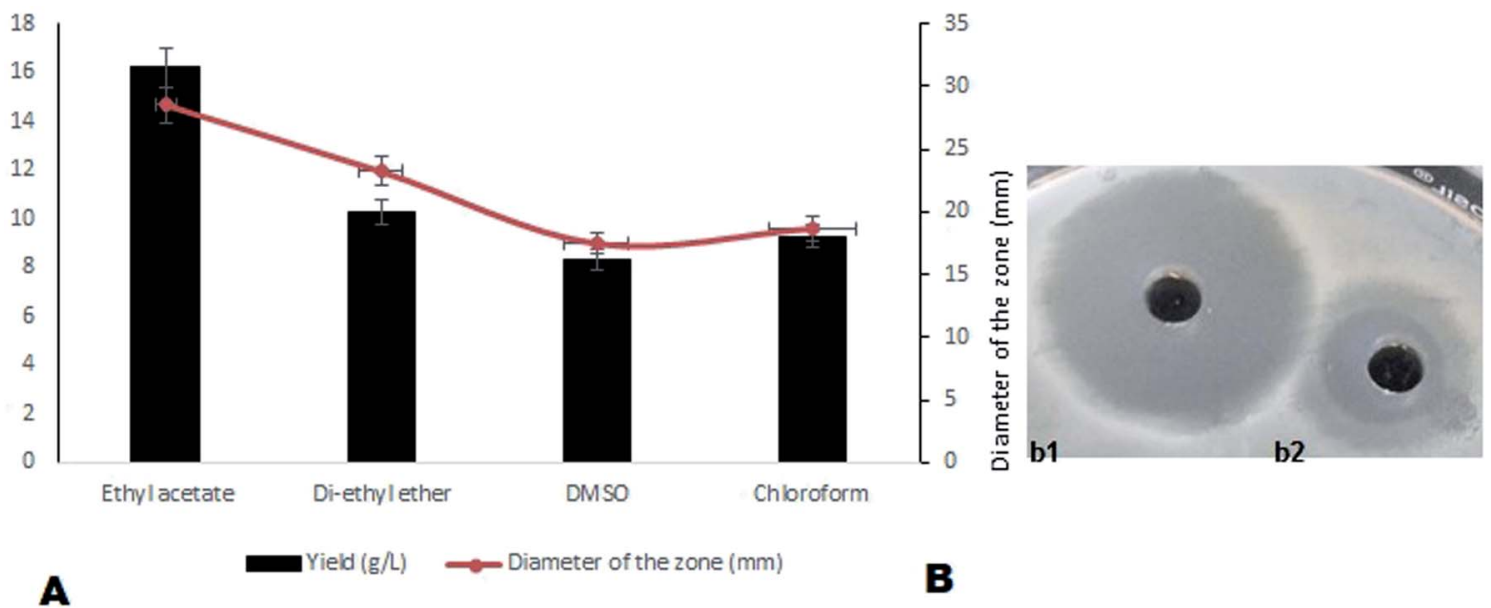

Fig. 3 (A) The solvents used for extraction and it was observed that ethyl acetate enhances the yield of antimicrobial compound and (B) (b1) shows the zone of inhibition of optimized MSI45 against MDRSA and (b2) shows the zone of inhibition before optimization of the compound MSI45

percentage of radical scavenging was calculated using the below mentioned formula.

$$
\text { AA }(\%)=\left[\left(\text { Abs. }_{\text {control }}-\text { Abs. }_{\text {sample }}\right) / \text { Abs. }_{\text {control }}\right] \times 100
$$

\subsection{MTT assay}

Mouse embryo fibroblast cell line was purchased from NCCS, Pune and the cells were maintained in DMEM - high glucose medium. To the 96-well plate $200 \mu \mathrm{l}$ of cell suspension was seeded at a required cell density (20 000 cells per well) and the

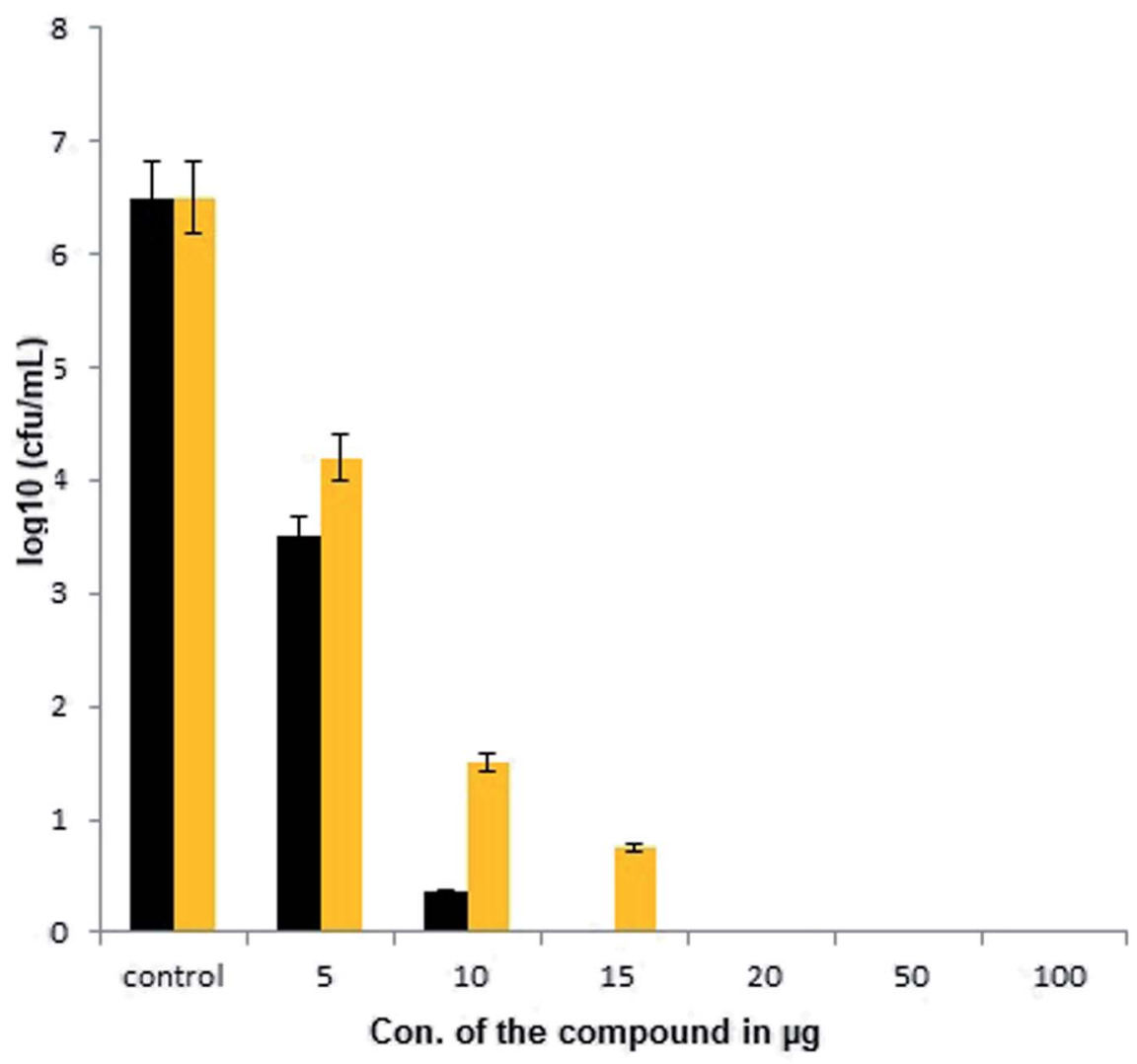

MIC

Fig. 4 Minimal inhibitory and minimal bactericidal concentration of the compound MSI45. 


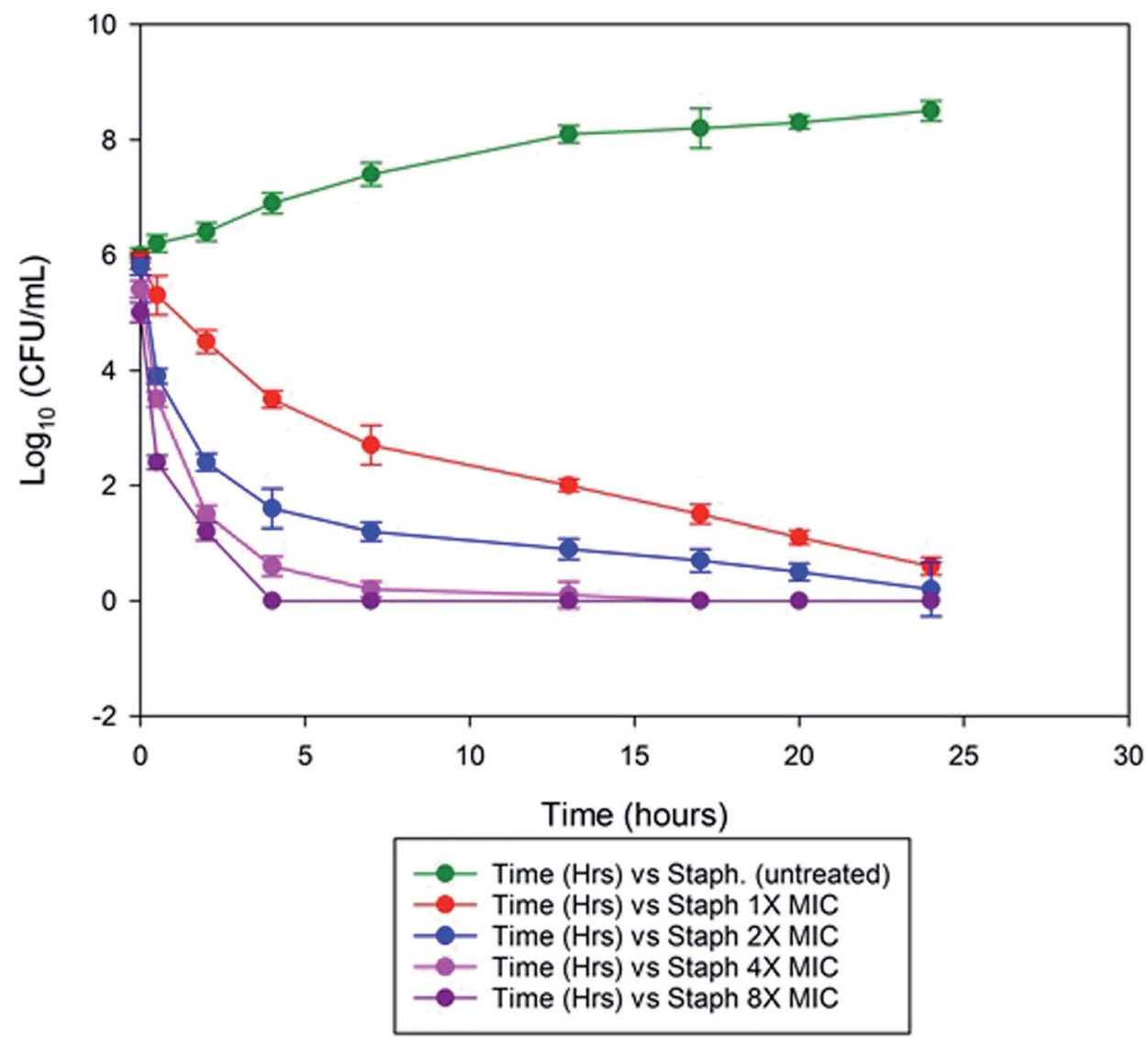

Fig. 5 Time kill assay showed the inhibition of the $S$. aureus by the extracted compound at $1 \times$ MIC, $2 \times M I C, 4 \times M I C$ and $8 \times M I C$. At $1 \times$ MIC the complete inhibition was achieved within 24 h of incubation and when MIC was increased to $4 \times$ and $8 \times$ the bactericidal effect was noticed within $2 \mathrm{~h}$ of incubation.

cells were allowed to grow for about $12 \mathrm{~h}$. To these cells MSI45 of different concentrations $10,25,50,100,200 \mathrm{mg} \mathrm{L}^{-1}$ was added and the plates were incubated at $37{ }^{\circ} \mathrm{C}$ in a humidified atmosphere (5\% $\mathrm{CO}_{2}$ and $95 \%$ air). After incubation, MTT reagent was added to the plates to make a final concentration of $0.5 \mathrm{mg} \mathrm{ml}^{-1}$ and the plates were again incubated for $3 \mathrm{~h}$. The MTT reagent was removed and then $100 \mu \mathrm{l}$ of solvent (DMSO) was added. The absorbance was read on a microtitre well plate spectrophotometer at $570 \mathrm{~nm}$ and $630 \mathrm{~nm}$ (Biotek Instruments, USA). The values of the percentages of cell viability were plotted against MSI45 concentrations, and $\mathrm{CC}_{50}$ was determined.

\section{Results}

\subsection{Isolation and characterisation of sponge associated bacteria}

A total of 56 marine bacteria were isolated from the marine sponge Callyspongia diffusa and were screened for antimicrobial activity against $S$. aureus. The pathogen $S$. aureus used in this study was resistant to all antibiotics tested which include vancomycin, penicillin, gentamycin, kanamycin, oxacillin, streptomycin and chloramphenicol. Among the isolates screened MSI45 showed antibacterial effect with a clear zone of inhibition $(22 \mathrm{~mm})$. The selected isolate MSI45 was characterized as Gram positive, non-motile, non-haemolytic, and catalase, protease and phospholipase negative. The isolate MSI45 was found to be sensitive to all the antibiotics tested such as ampicillin, chloramphenicol, tetracycline, and oxacillin. Taxonomic affiliation of the isolate MSI45 based on 16S rRNA sequencing revealed the isolate has closest association with Bacillus tequilensis (Fig. 1). The BLASTn analysis showed 99\% identity with B. tequilensis, B. velezensis and B. subtilis. Based on the biochemical characteristics and halophilic nature of MSI45, the strain was tentatively identified as B. tequilensis. This work is the first report to identify $B$. tequilensis from a marine sponge.

\subsection{Optimization and extraction of the antimicrobial compound MSI45}

On optimization of various production media nutrient agar supplemented with $2 \% \mathrm{NaCl}$ showed high production of antimicrobial compounds when compared to Zobell marine broth, marine modified broth, LB broth and starch casein broth. A maximum yield of $10.2 \mathrm{~g} \mathrm{~L}^{-1}$ was obtained on the nutrient broth media supplemented with $2 \% \mathrm{NaCl}$ with a zone of inhibition of $23.2 \mathrm{~mm}$ (Fig. 2a). The yield of antimicrobial compound MSI45 was further improved on addition of various carbon and nitrogen sources. We observed that the media supplemented with $1 \%$ 

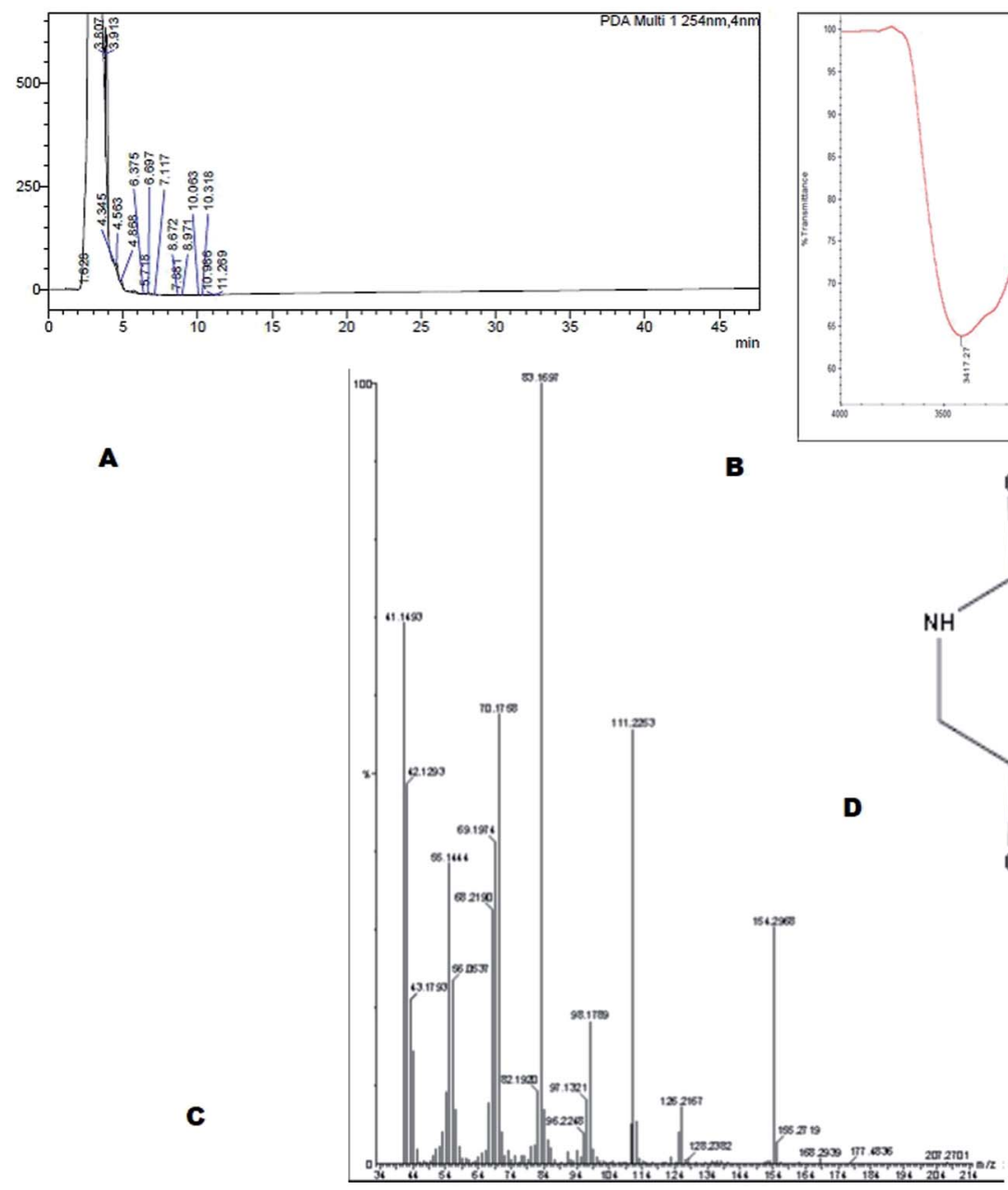
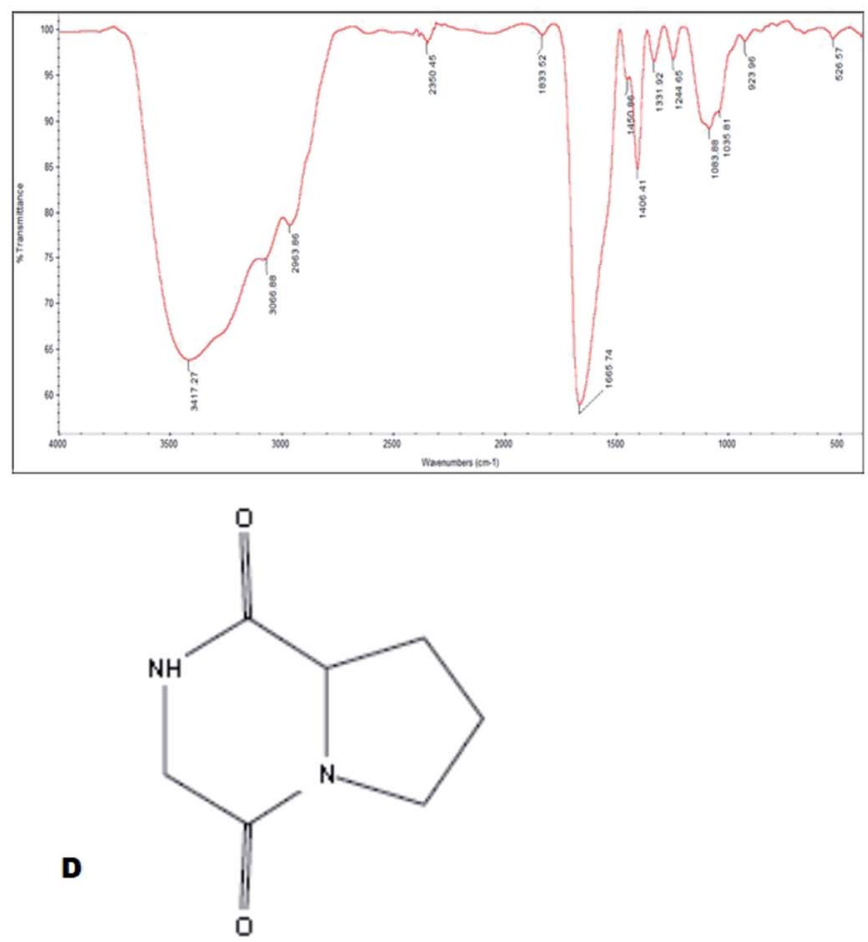

Fig. 6 (A) Purification of the compound using HPLC and (B) FTIR analysis shows the functional groups of the compound MSI45 (C) mass spectral analysis of the compound using GCMS and (D) predicated structure of the compound MSI45 as pyrrolo[1,2-a]pyrazine-1,4-dione,hexahydro.

each of glucose and peptone increases the yield of the compound MSI45. The effect of different concentration of carbon and nitrogen sources on antimicrobial activity showed $2 \%$ glucose and $1 \%$ peptone was optimum for the growth and for the yield of $15 \mathrm{~g} \mathrm{~L}^{-1}$ with a diameter of zone of inhibition of $28 \mathrm{~mm}$ (Fig. $2 \mathrm{~b}$ ). Physical parameters such as temperature, incubation time and $\mathrm{pH}$ were also optimized. We observed a temperature of $30^{\circ} \mathrm{C}$ with an incubation time of $96 \mathrm{~h}$ and a pH of 7.0 to be suitable for the yield of antimicrobial compound (Fig. 2c).

\subsection{Solvent optimization}

On optimization of solvents for the extraction of compound MSI45, ethyl acetate was found to be the most suitable solvent followed by diethyl ether and DMSO. A maximum yield of $16.2 \mathrm{~g}$ $\mathrm{L}^{-1}$ of antimicrobial compound was recovered from the media using ethyl acetate. The activity of the ethyl acetate extracted compound was tested by a well diffusion assay and the results obtained are shown in Fig. 3. The extracted compound was found to be non-haemolytic and therefore it can be used for clinical applications.

\subsection{Determination of MIC and MBC}

The extracted compound MSI45 showed potent inhibitory effect on MDRSA strain with an MIC of $15 \pm 0.172 \mathrm{mg} \mathrm{L}^{-1}$ and MBC of $20 \pm 0.072 \mathrm{mg} \mathrm{L}^{-1}$ (Fig. 4). The MIC and MBC ratio was found to be 0.75 and hence the compound was identified as bactericidal.

\subsection{Time kill assay}

We observed the minimal inhibitory effect of MSI45 against $S$. aureus was $15 \pm 0.172 \mathrm{mg} \mathrm{L}^{-1}$. In the time kill assay, the killing rate of MSI45 increased with increase in the concentration of MIC. At $1 \times$ MIC of MSI 45 the complete killing of $S$. aureus cells was achieved at $24 \mathrm{~h}$, at 4 and $8 \times$ MIC the bactericidal effect was well noticed within $2 \mathrm{~h}$ of incubation (Fig. 5). The CFU was reduced by $7 \log$ units indicating the fast killing effect of MSI45. The time kill kinetics showed a dose dependent bactericidal effect on MDRSA, when the dose of the compound was increased the death of the $S$. aureus cells was achieved indicating the potent antimicrobial effect of the extract MSI45. 


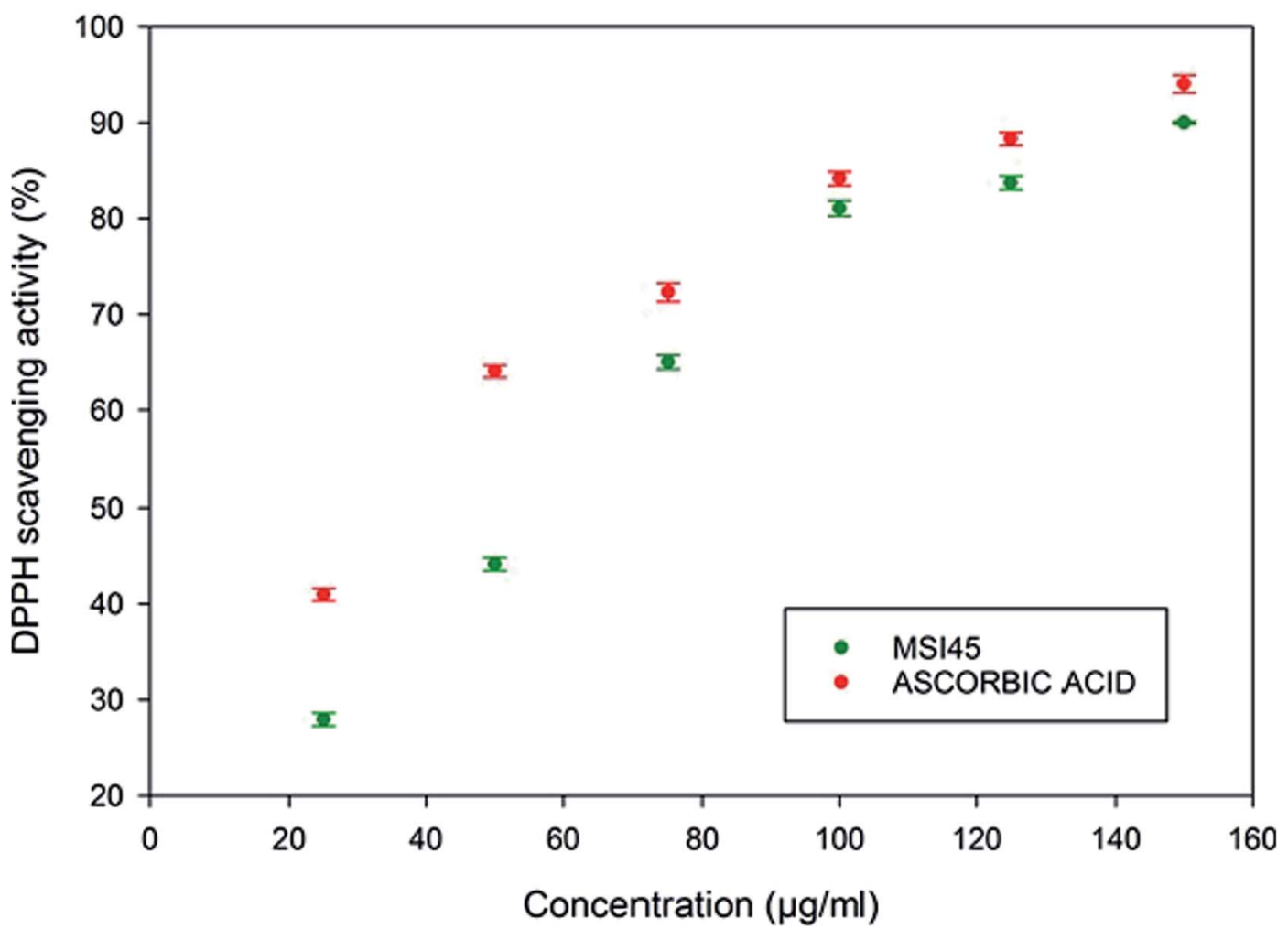

Fig. 7 Antioxidant activity of the compound MSI45 using DPPH assay. The assay shows the antioxidant activity increases with increase in the concentration of the compound.

\subsection{Characterization of antimicrobial compound MSI45}

The bioactive compound MSI45 was purified by a HPLC which showed an elution peak at the retention time of $3.11 \mathrm{~min}$ (Fig. 6A). The eluted active compound from MSI45 was found to be non-hemolytic on blood agar plates (ESI Fig. $1 \dagger$ ). The FTIR spectrum of the compound MSI45 showed characteristic functional groups at $3417-3060 \mathrm{~cm}^{-1}$ corresponding to amine $\mathrm{N}-\mathrm{H}$ stretch, peak at $2963 \mathrm{~cm}^{-1}$ corresponding to alkyl C-H stretch, carbonyl group at $1665 \mathrm{~cm}^{-1}$ and $\mathrm{C}-\mathrm{O}$ bonds at 1450$1244 \mathrm{~cm}^{-1}$ respectively (Fig. 6B). The GC-MS analysis was performed to determine the active molecule of MSI45. The analysis showed presence of four compounds in the sample on comparison of the mass spectra, molecular weight, retention

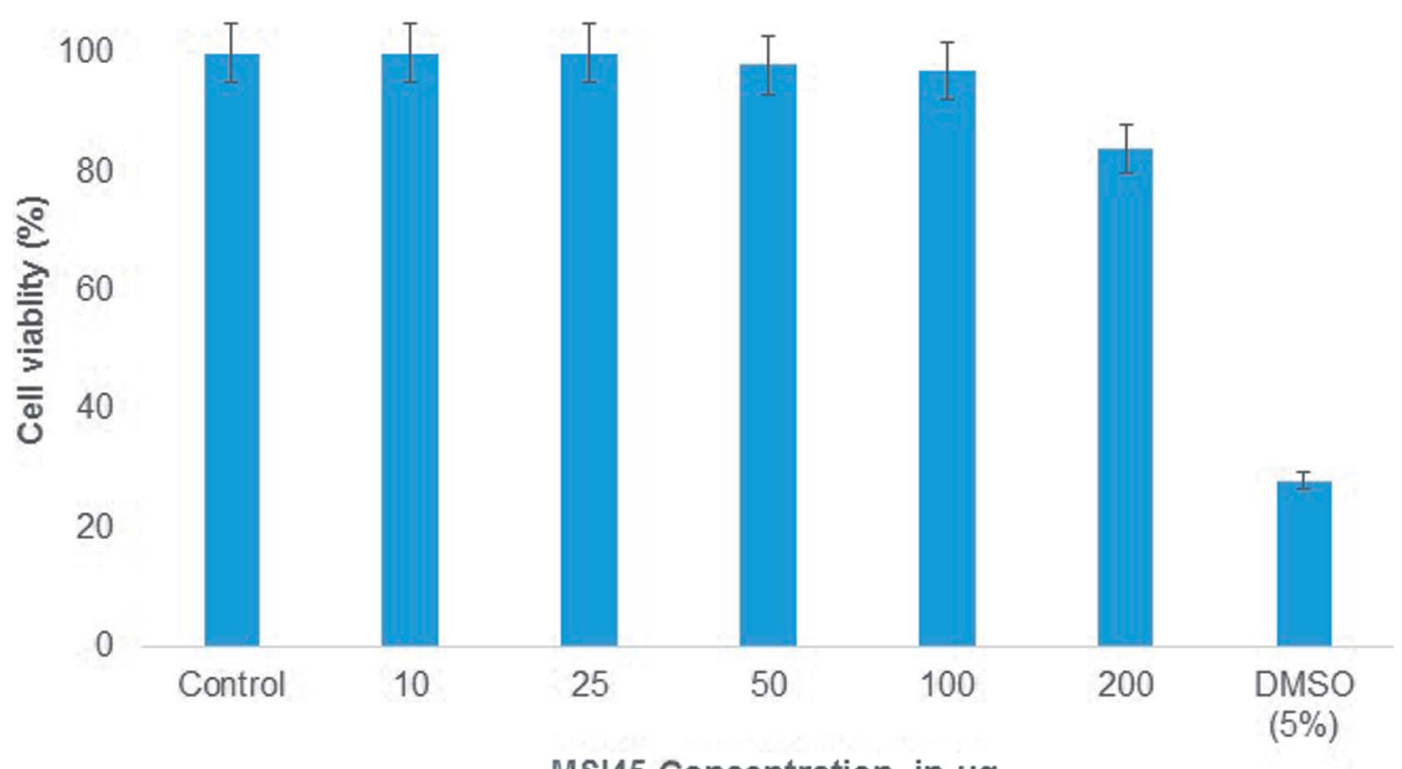

Fig. 8 The MTT assay showed nontoxic nature of the compound MSI45. 
time and molecular formula with the NIST library. The spectra showed a major peak at 16.9 min the mass spectrum analysis showed it has a molecular weight of $154 \mathrm{Da}$ with a molecular formula of $\mathrm{C}_{7} \mathrm{H}_{10} \mathrm{O}_{2} \mathrm{~N}_{2}$ (pyrrolo[1,2- $\left.a\right]$ pyrazine-1,4dione,hexahydro) (Fig. 6C). The peak area corresponds to the quantity of the compound present in the sample. The ${ }^{1} \mathrm{H}-\mathrm{NMR}$ spectrum (400 MHz, DMSO) showed signals at $\delta_{\mathrm{H}} 1.8-2.3$ corresponding to $4 \mathrm{H}$, and also a $(2 \mathrm{H})$ peak at 3.5-3.6 and signals at $3.8(\mathrm{~d}, 1 \mathrm{H}), 3.9(\mathrm{~d}, 1 \mathrm{H}), 4.1(\mathrm{dd}, 1 \mathrm{H})$ and $7.1(1 \mathrm{H}, \mathrm{S})$ The ${ }^{13} \mathrm{C}$ NMR spectrum showed signals at $\delta 22.23,28.93,45.78,46.01,58.04$, 164.63, 169.51 (ESI Fig. S2 $\dagger$ ). The NMR, FT-IR and GC-MS spectral data helped in identification of the compound MSI45 as pyrrolo[1,2-a]pyrazine-1,4-dione,hexahydro.

\subsection{DPPH scavenging assay}

The antioxidant activity of the compound MSI45 was tested using a DPPH scavenging assay. The free radical scavenging activity of the compound increased in a dose dependent manner. The activity increased from low concentration of 25$125 \mu \mathrm{g} \mathrm{m}{ }^{-1}$. The scavenging activity of the compound was found to be $27.95 \pm 0.68$ for $25 \mu \mathrm{g}$ and $90 \pm 0.12$ for $125 \mu \mathrm{g} \mathrm{ml}$ (Fig. 7). The antioxidant activity of the compound MSI45 was much similar when compared to the standard ascorbic acid at higher concentration of $75-100 \mu \mathrm{g} \mathrm{ml}^{-1}$. This trend shows an increase in the concentration of the compound MSI45 has a significant higher antioxidant activity.

\subsection{Cell line studies}

MTT assay was performed to determine the toxicity of the compound MSI45 to the cell line. The mouse embryo fibroblast cell line was treated with varying concentration of the compound MSI45 and the results obtained showed high viability rates as compared to the control. On an average of the triplicate experiment, $97 \%$ viability was achieved up to $100 \mathrm{mg} \mathrm{L}^{-1}$ and $84 \%$ viability in $200 \mathrm{mg} \mathrm{L}^{-1}$ (Fig. 8). Thus, the obtained $\mathrm{CC}_{50}$ values showed that the antimicrobial compound MSI45 can be suitable for systemic application.

\section{Discussion}

Marine sponges are the richest source of antimicrobial compounds such as terpenoids, peptides, polysaccharides, polyketides, fatty acids, steroids, alkaloids and phenolic compounds. The alkaloids produced by the sponges have nitrogen containing heterocyclic compounds which include bromopyrrole, pyrroloiminoquinone and alkylpiperidine alkaloids. ${ }^{29}$ The sponge Callyspongia diffusa used in this study for bacterial isolation was known for the production of antimicrobial compounds ${ }^{30}$ and the bacteria isolated from the sponges were reported for the production of antifouling, biosurfactant and antibacterial compounds. ${ }^{31}$ Most of the bacteria associated with sponges were endosymbiotic and provide a major source of bioactive molecules. Marine Bacillus species were well known for the production of bioactive compounds especially macrolactin $^{32}$ and biosurfactants. In this study a total of 56 bacteria were isolated from the marine sponge and they were screened for the antibacterial activity against multidrug resistant $S$. aureus. We identified and isolated a novel B. tequilensis MSI45 which showed inhibitory effect against $S$. aureus. A probiotic strain of B. tequilensis FR9 has been isolated from the gastrointestinal tract of chicken without any haemolytic activity and was found to be tolerant in acid and bile test. ${ }^{33} \mathrm{~A}$ sponge isolate Bacillus SEB32 produced antimicrobial agent in the Zobell marine broth supplemented with $35 \% \mathrm{NaCl}$ on $9^{\text {th }}$ day of incubation. ${ }^{34}$ The isolate used in this study B. tequilensis MSI45 produced a antimicrobial compound on $4^{\text {th }}$ day of incubation with an inhibition zone of $28 \mathrm{~mm}$. On optimization of solvents for the extraction of bioactive molecule ethyl acetate was found to be most suitable and recovered the maximum yield of the compound $16.2 \mathrm{~g} \mathrm{~L}^{-1}$. Based on FT-IR, GC-MS and NMR characterization of the bioactive molecule from $B$. tequilensis it was observed that the active molecule was pyrrole with its substitute as pyrrolo[1,2-a]pyrazine-1,4-dione,hexahydro. The peaks and the functional groups in FT-IR were similar to the study reported. ${ }^{35}$ Pyrrole was known for various therapeutic applications and has been used as antibiotics, antitumour, antifungal, anti-inflammatory and cholesterol reducing drugs. Pyrrole has also been the ability to inhibit HIV-1 viruses and DNA polymerases and protein kinase activity. ${ }^{36-38}$ Pyrrole along with its substitute, pyrazine protects the seizures and is used as a potent anticonvulsant drug. ${ }^{39}$ A Streptomyces strain isolated from mangrove soil has been reported to produce pyrrolo[1,2- $a$ ] pyrazine-1,4-dione,hexahydro showed antioxidant property of $32 \%$ in $1 \mathrm{mg} \mathrm{ml}^{-1}$ of the compound ${ }^{40}$ whereas the antioxidant property of the compound produced by MSI45 was much higher of $81 \%$ in $0.1 \mathrm{mg} \mathrm{ml} \mathrm{m}^{-1}$. In the time kill assay the complete inhibition of $S$. aureus was achieved at $1 \times, 4 \times$ and $8 \times$ MIC within 24 and $2 \mathrm{~h}$ of incubation. A study by Li et al. ${ }^{\mathbf{4 1}}$ reported hexahydropyrrolo[1,2-a]pyrazine-1,4-dione as an algicidal agent against Microcystis aeruginosa.

\section{Conclusions}

In this study a marine sponge $C$. diffusa associated bacteria $B$. tequilensis was isolated, identified and optimized to produce antibiotic compound that acted on MDRSA. The spectroscopic analysis revealed the bioactive metabolite as a pyrrolo[1,2- $a]$ pyrazine-1,4-dione,hexahydro. This molecule was nonhemolytic and showed antioxidant activity. Therefore, it was concluded that the molecule produced by B. tequilensis MSI45 can be developed as an effective antibiotic against infections caused by MDRSA.

\section{Author contributions}

JS designed, monitored and written the paper. GSK guided all experimental works. SP and AS performed lab experiments.

\section{Conflicts of interest}

There are no conflicts of interest to declare. 


\section{Acknowledgements}

GSK is thankful to the Department of Science and Technology (DST) for a project grant. JS is thankful to the DBT project on the exploration of marine sponge microbiome.

\section{References}

1 A. Magiorakos, A. Srinivasan, R. B. Carey, Y. Carmeli, M. E. Falagas, C. G. Giske, S. Harbarth, J. F. Hindler, G. Kahlmeter and B. Olsson-Liljequist, Clin. Microbiol. Infect., 2012, 18, 268-281.

2 A. Mearns Spragg, M. Bregu, K. G. Boyd and J. G. Burgess, Lett. Appl. Microbiol., 1998, 27, 142-146.

3 J. Selvin, J. Kennedy, D. P. H. Lejon, G. S. Kiran and A. D. W. Dobson, Microb. Cell Fact., 2012, 11, 72.

4 J. W. Blunt, B. R. Copp, W.-P. Hu, M. H. Munro, P. T. Northcote and M. R. Prinsep, Nat. Prod. Rep., 2007, 24, 31-86.

5 J. W. Blunt, B. R. Copp, M. H. G. Munro, P. T. Northcote and M. R. Prinsep, Nat. Prod. Rep., 2005, 15-61.

6 S. Pandey, A. Sree, D. P. Sethi, C. G. Kumar, S. Kakollu, L. Chowdhury and S. S. Dash, Microb. Cell Fact., 2014, 13, 24.

7 J. Selvin, G. Sathiyanarayanan, A. N. Lipton, N. A. Al-Dhabi, M. V. Arasu and G. S. Kiran, Front. Microbiol., 2016, 7, 63.

8 M. R. Rao and D. J. Faulkner, J. Nat. Prod., 2002, 65, 386-388. 9 J. W. Blunt, B. R. Copp, W. Hu, M. H. G. Munro, P. T. Northcote and M. R. Prinsep, Nat. Prod. Rep., 2007, 24, 31-86.

10 D. Sipkema, M. C. R. Franssen, R. Osinga, J. Tramper and R. H. Wijffels, Mar. Biotechnol., 2005, 7, 142.

11 M. Donia and M. T. Hamann, Lancet Infect. Dis., 2003, 3, 338348.

12 S. Matsunaga and N. Fusetani, Curr. Org. Chem., 2003, 7, 945-966.

13 N. Fusetani, Nat. Prod. Rep., 2004, 21(1), 94-104.

14 R. A. Keyzers and M. T. Davies-Coleman, Chem. Soc. Rev., 2005, 34, 355-365.

15 B. S. Moore, Nat. Prod. Rep., 2006, 23, 615-629.

16 J. Piel, Curr. Med. Chem., 2006, 13, 39-50.

17 T. Matsunaga, R. Tomoda, T. Nakajima and H. Wake, FEMS Microbiol. Lett., 1985, 29, 211-214.

18 E. Sansinenea and A. Ortiz, Biotechnol. Lett., 2011, 33, 15231538.

19 T. Stein, Mol. Microbiol., 2005, 56, 845-857.

20 E. Hodille, W. Rose, B. A. Diep and O. Dumitrescu, Clin. Microbiol. Rev., 2017, 4, 887-917.

21 J. Selvin, S. Shanmughapriya, R. Gandhimathi, K. G. Seghal, T. Rajeetha Ravji, K. Natarajaseenivasan and T. A. Hema, Appl. Microbiol. Biotechnol., 2009, 83, 435-445.

22 R. Gandhimathi, M. Arunkumar, J. Selvin, T. Thangavelu, S. Sivaramakrishnan, G. S. Kiran, S. Shanmughapriya and K. Natarajaseenivasan, J. Mycol. Med., 2008, 18, 16-22.

23 N. A. Logan and R. C. W. Berkley, J. Gen. Microbiol., 1984, 130, 1871-1882.
24 G. S. Kiran, S. Priyadharshini, A. Sajayan, G. B. Priyadharshini, N. Poulose and J. Selvin, Front. Microbiol., 2017, 8, 1138.

25 R. Leclercq, R. Canton, D. F. Brown, C. G. Giske, P. Heisig, A. P. MacGowan, J. W. Mouton, P. Nordmann, A. C. Rodloff, G. M. Rossolini, C. J. Soussy, M. Steinbakk, T. G. Winstanley and G. Kahlmeter, Clin. Microbiol. Infect., 2013, 2, 141-160.

26 European Committee for Antimicrobial Susceptibility Testing (EUCAST) of the European Society of Clinical Microbiology and Infectious Diseases (ESCMID), Clin. Microbiol. Infect., 2000, 6, 503-508.

27 I. R. Sharafutdinov, E. Y. Trizna, D. R. Baldamshina, M. N. Ryzhikova, M. N. Ryzhikova, R. R. Sibgatullina, A. M. Khabibrakhmanova, L. Z. Lapypova, A. R. Kurbangalieva, E. V. Rozhina, M. K. Strobel, R. F. Fakhrullin, M. W. Pletz, M. I. Bogachev, A. R. Kayumov and O. Makarewicz, Front. Microbiol., 2017, 8, 2246.

28 N. Turkmen, F. Sari and Y. S. Velioglu, Food Chem., 2006, 99, 835-841.

29 M. J. Abad, L. M. Bedoya, and P. Bermejo, in Science against Microbial Pathogens: Communicating Current Research and Technological Advances, ed. A. Mendez-Vilas, FORMATEX, Badajoz, Spain, 1st edn, 2011, 51, pp. 1293-1306.

30 R. Gandhimathi, M. Arunkumar, J. Selvin, T. Thangavelu, S. Sivaramakrishnan, G. S. Kiran, S. Shanmughapriya and K. Natarajaseenivasan, J. Mycol. Med., 2008, 18, 16-22.

31 R. S. Rachana, A. P. Lipton and V. Thankamani, Antibacterial and Antifouling activity of the Marine Sponge Callyspongia diffusa collected from south-west coast of India, Int. J. Biochem. Biotechnol., 2016, 12, 33-42.

32 A. Dhasayan, J. Selvin and S. Kiran, 3 Biotech., 2015, 5, 443454.

33 X. L. Lu, Q. Z. Xu, Y. H. Shen, X. Y. Liu, B. H. Jiao, W. D. Zhang and K. Y. Ni, Nat. Prod. Res., 2008, 22, 342-347.

34 R. P. Rani, M. Anandharaj, P. Sabhapathy and A. D. Ravindran, Int. J. Biol. Macromol., 2017, 96, 1-10.

35 G. Mohan, A. K. T. Thangappanpillai and B. Ramasamy, Biotechnol. Rep., 2016, 11, 44-52.

36 R. P. Wurz and A. B. Charette, Org. Lett., 2005, 7, 2313-2316. 37 C. Piliego, T. W. Holcombe, J. D. Douglas, C. H. Woo, P. M. Beaujuge and J. M. J. Fréchet, J. Am. Chem. Soc., 2010, 132, 7595-7597.

38 V. Bhardwaj, D. Gumber, V. Abbot, S. Dhiman and P. Sharma, RSC Adv., 2015, 5, 15233-15266.

39 M. Dawidowski, F. Herold, A. Chodkowski, J. Kleps, P. Szulczyk and M. Wilczek, Eur. J. Med. Chem., 2011, 46, 4859-4869.

40 H.-L. Ser, U. D. Palanisamy, W.-F. Yin, S. N. A. Malek, K.-G. Chan, B.-H. Goh and L.-H. Lee, Front. Microbiol., 2015, 6, 854 .

41 Z. Li, M. Geng and H. Yang, Appl. Microbiol. Biotechnol., 2014, 2, 981-990. 